\title{
Arc-Jet Testing of Ultra-High-Temperature-Ceramics
}

\author{
Raffaele Savino, Mario De Stefano Fumo*, Diego Paterna and Di Maso Andrea
}

Dipartimento di Ingegneria Aerospaziale, University of Naples “Federico II”, P.le V. Tecchio 80, 80125 Naples, Italy

\begin{abstract}
The article deals with arc-jet experiments on different Ultra High Temperature Ceramics models in high enthalpy hypersonic non equilibrium flow. Typical geometries for nose tip or wing leading edges of interest for hypersonic vehicles, as rounded wedge, hemisphere and cone are considered. Temperature measurements have been performed using pyrometers, an IR thermocamera and thermocouples. Spectral emissivity has been evaluated by suitable experimental techniques. The details of the experimental set-up, the tests procedure and the measurements are discussed in the text. The UHTC materials have been tested for several minutes to temperatures up to $2050 \mathrm{~K}$ showing a good resistance in extreme conditions. Fundamental differences between the various model shapes have been analysed and discussed. Numerical-experimental correlations have been carried out by a CFD code, resulting in good agreement with proper modelling. The numerical rebuilding also allowed to evaluate the catalytic efficiency and the emissivity of the materials at different temperature.
\end{abstract}

Keywords: Atmospheric reentry, ultra-high temperature materials, arc-jet testing, aerothermodynamics, computational fluid dynamics.

\section{INTRODUCTION}

Re-entry from Low Earth Orbit (e.g. ISS crew re-entry, spaceplanes, Space Tourism) and from Space Exploration missions (e.g. from Moon, Mars) requires careful considerations about system concept design and trajectory definition, especially when the objective is to improve the safety aspect of the mission.

Recently an alternative way to re-enter Earth atmosphere, improving safety and lowering maintenance costs, has been proposed based on slender vehicles with sharp edges, flying at moderate angles of attack. Sharp leading edges would also imply lower aerodynamic drag, improved flight performances and crew safety, due to the larger cross range and maneuverability along with more gentle re-entry trajectories [1-4]. The temperature at the tip of the leading edge is inversely proportional to the square root of the leading edge nose radius and the reduced curvature radius results in higher surface temperature than that of the actual blunt vehicles that could not be withstood by the conventional thermal protection system materials. A new class of ceramic materials the Ultra High Temperature Ceramics (UHTC) has been proposed for TPS based on hot structure concept. Metallic diborides, as Zirconium, Hafnium and Titanium with different additives, are candidates for thermal protection materials in both re-entry and hypersonic cruise vehicles because of their high melting points $(>3000$ $\left.{ }^{\circ} \mathrm{C}\right)$ and excellent chemical stability [5-9]. These materials are also characterized by high hardness, high electrical and thermal conductivity; in particular the relatively high thermal

\footnotetext{
*Address correspondence to this author at the Dipartimento di Ingegneria Aerospaziale, University of Naples "Federico II", P.le V. Tecchio 80, 80125 Naples, Italy; Tel: 00390817682357; Fax: 00390817682351;

E-mail: madestef@unina.it
}

conductivity is useful in order to reduce the stagnation point temperature. Indeed, when considering re-entering bodies, the convective heat transfer entering the surface is partly conducted to the solid and partly re-radiated into the atmosphere. When a steady state is achieved, global radiative equilibrium is established, in the sense that the (surface) overall convective heat flux is perfectly balanced by the overall surface radiative flux and if the material thermal conductivity is high a relatively lower equilibrium temperature is achieved.

The heat flux distribution over typical geometries of nose and wing leading edge of space vehicles, exhibits the typical dependence by the inverse of the square root of the distance (x) from the stagnation point and therefore decreases by increasing boundary layer thickness (boundary layer thermal protection) $[10,11]$. Thus there is a relatively small heat flux at distances sufficiently downstream of the leading edge. This suggest the adoption of a massive thermal protection system only in the tip region of the vehicle, while the remaining major part of the vehicle's surface can be free from heavy protections.

In this paper, arc-jet tests are carried out on tree models with different geometries ( a rounded wedge with $4 \mathrm{~cm}$ length, a small hemisphere and a sharp cone). All models are of the same material (composite Zirconium Diboride/Silicon Carbide ceramic, $\mathrm{ZrB}_{2}$-SiC).

Recent studies have pointed out that this material can be fabricated by hot pressureless sintering and machined in the desired shape by electroerosion; in particular, the addition of $\mathrm{SiC}$ or $\mathrm{MoSi}_{2}$ as sintering aid allows the achievement of highly dense bodies at relatively high temperature by pressureless sintering and at the same time improves the oxidation resistance due to the development of a silica protective coating $[12,13]$. 
Arc-jet testing represents the best ground-based simulation of a re-entry environment, in different ways. On one hand, it provides the possibility to explore the oxidation behaviour of these materials under extreme conditions. On the other hand, the materials response to large heat fluxes is evaluated through the determination of two important parameters, i.e. emissivity and catalytic efficiency. High values of emissivity and low values of surface catalytic efficiency are desired for the above mentioned applications as they reduce temperature gradients and thermal stresses in the structure, thus enabling the vehicle to operate under relatively high enthalpy flow conditions.

The arc-jet tests reported in $[14,15]$ have been carried out at relatively high total enthalpy (typical of atmospheric reentry environment) but at atmospheric pressure (i.e. in subsonic flow conditions). The surface temperature and emissivity of the materials were evaluated during the test and fluid dynamic numerical simulations were carried out to evaluate the catalytic atom recombination efficiencies of the materials at the experimental conditions; the numerical results correlated quite well with experimental ones assuming a low catalytic surface behaviour.

The microstructure modifications, analysed after exposure on the surface and cross sections of the samples pointed out the potential of these composites to endure re-entry conditions with temperature approaching $2000{ }^{\circ} \mathrm{C}$ or even higher.

The objectives of the present experiments are to characterize the behavior of UHTC models in real hypersonic nonequilibrium conditions typical of atmospheric reentry and in particular: 1) to investigate the boundary layer thermal protection in a relatively sharp configuration (a rounded wedge with $4 \mathrm{~cm}$ length and $5 \mathrm{~mm}$ curvature radius) and 2) to characterize the behavior of the UHTC material at relatively high temperature, low pressure and oxidizing environment typical of atmospheric re-entry (after exposure of small-sized spherical and conical specimens at extreme temperature conditions).

Fluid dynamic numerical simulations are carried out in order to rebuild, through computational fluid dynamic (CFD) modeling, all the experimental tests and to evaluate the catalytic efficiency of the material with respect to oxygen and nitrogen surface recombination reactions.

\section{ARC-JET TESTING OF UHTC ROUNDED WEDGE}

\subsection{Test Model}

During the first test a UHTC rounded wedge was exposed at two different flow conditions with two different angle of attack $\left(0^{\circ}\right.$ and $\left.25^{\circ}\right)$.

The test model has a length of $40 \mathrm{~mm}$, a wedge angle of $4^{\circ}$ and a curvature radius of $5 \mathrm{~mm}$ (Fig. 1). The UHTC model was machined from a single piece (a massive cylinder). The model was inserted in a copper support to interface with the facility support system. For the condition at an angle of attack of $25^{\circ}$ a copper adapter has been applied to the support. The model was held in position by a mechanical arm and the winglet leading edge located $12 \mathrm{~cm}$ away from the nozzle exit.

In particular the UHTC model was drilled by electroerosion to obtain two holes for the inner thermocouples.

The temperature evolution of the model surface was measured by a ratio pyrometer Maurer $\mathrm{GmbH}$ Optoelektronik, Q-PMRS-65-d (temperature range $800{ }^{\circ} \mathrm{C}$ $2000{ }^{\circ} \mathrm{C}$, spectral range $0.85-1.1 ; 0.95-1.1$ micron; accuracy $1 \%$, Single wavelength pyrometer Maurer $\mathrm{GmbH}$ Optoelektronik, TMRS-85-2-d (temperature range $900{ }^{\circ} \mathrm{C}$ $2000{ }^{\circ} \mathrm{C}$, spectral range $0.85-1.1$ micron, accuracy $1 \%$ ), single wavelength pyrometer Minolta, Cyclops 152A (temperature range $550{ }^{\circ} \mathrm{C}-3000{ }^{\circ} \mathrm{C}$, spectral range $0.7-1.1$ micron, accuracy $1 \%$ ) and by an infrared thermocamera, AGEMA Thermovision 570 (temperature range $350{ }^{\circ} \mathrm{C}-2000$ ${ }^{\circ} \mathrm{C}$, spectral range 8-14 micron, accuracy $2 \%$ ).

Three type $\mathrm{K}$ thermocouples were mounted into the specimen, two at $16 \mathrm{~mm}$ and $30 \mathrm{~mm}$ from the leading edge, the third one to measure the temperature at the UHTCcopper interface junction.

\subsection{Facility}

The experimental tests have been carried out in the L2K facility available at DLR of Cologne (Germany). The facility is an arc-heated (huels type) plasma wind tunnel which is described in detail by Esser and Guhelan [16]. Mass flow rates are in the range between $5 \mathrm{~g} / \mathrm{s}$ and $75 \mathrm{~g} / \mathrm{s}$, the maximum total pressure is $1.8 \mathrm{bar}$, and the maximum total enthalpy $20 \mathrm{MJ} / \mathrm{Kg}$.
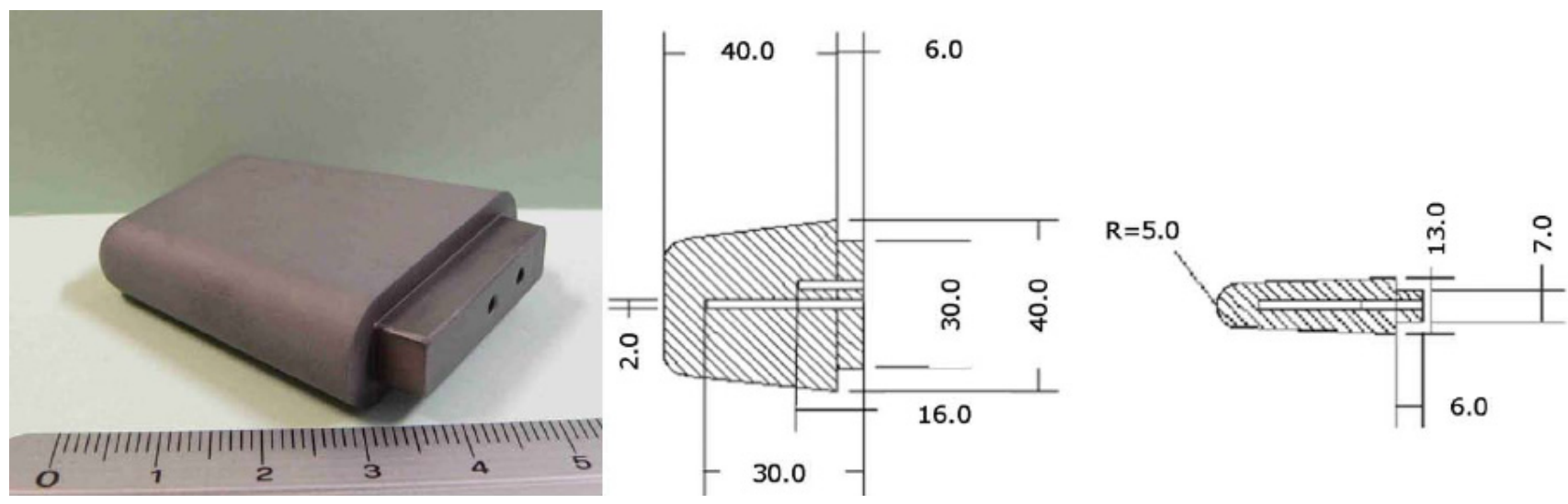

Fig. (1). Image and drawings (mm) of the model with the thermocouple holes. 
The nozzle geometry is characterized by a conical convergent $\left(35^{\circ}\right.$ half angle), a circular throat with diameter of $29 \mathrm{~mm}$, a conical divergent with $12^{\circ}$ half-angle terminating with a diameter of $100 \mathrm{~mm}$. The nominal Mach number at the exit is $M=3.9$. The Mach number calculated by CFD computations at the model location ( $\mathrm{x}=12 \mathrm{~cm}$ from the exit) is $\mathrm{M}=4.7$.

The facility is operated setting the electrical current (I) and the mass flow rate $(\dot{m})$, measured with a flow meter based on Coriolis effect, with accuracy of $1 \%$. The voltage $(\Delta \mathrm{V})$ depends by input parameter.

From mass flow rate and total pressure $\left(\mathrm{P}_{0}\right)$, assuming one-dimensional flow and chemical equilibrium, the specific total enthalpy $\left(\mathrm{H}_{0}\right)$ and all other thermo-fluid-dynamic reservoir properties may be obtained.

The two different selected test conditions, belonging to the facility operating envelope, are summarized in Table 1, labelled as FC-1 and FC-2. The model was held in position by a mechanical arm, and located $12 \mathrm{~cm}$ away from the nozzle exit. Mass flow rates, reservoir pressures, test chamber pressures, current and voltage are directly measured. In addition, pitot pressures $\left(\mathrm{p}_{02}\right)$ are measured at the model location. The test condition FC-2 for the rounded wedge has been performed with two different angle of attack $\left(0\right.$ and $\left.25^{\circ}\right)$.

Table 1. Rounded Wedge Test Conditions

\begin{tabular}{|c|c|c|}
\hline & FC1 & FC2 \\
\hline \hline$\dot{m}, \mathrm{~g} / \mathrm{s}$ & 45 & 50 \\
\hline $\mathrm{P}_{0}, \mathrm{mbar}$ & 1337 & 1245 \\
\hline $\mathrm{p}_{02}, \mathrm{mbar}$ & 80 & 74 \\
\hline $\mathrm{I}, \mathrm{A}$ & 954 & 500 \\
\hline$\Delta \mathrm{V}, \mathrm{V}$ & 780 & 927 \\
\hline $\mathrm{H}_{0}, \mathrm{Mj} / \mathrm{kg}$ & 9.7 & 6.05 \\
\hline
\end{tabular}

\subsection{Experimental Results}

Tests characterized by different duration (from 60 up to 180s) have been performed for each of the flow conditions (see Table 2).

During low-duration tests pyrometers measurements are not possible because the minimum temperature is $1000 \mathrm{~K}$, and only infrared images can be detected, with the temperature range of the thermocamera limited between 80 and $500{ }^{\circ} \mathrm{C}$. The long-duration tests were performed taking all the temperature measurements and setting the temperature range of the thermocamera between 500 and $2000{ }^{\circ} \mathrm{C}$.

Table 2. Tests Matrix

\begin{tabular}{|c|c|c|c|}
\hline Test Nr. & $\begin{array}{c}\text { Flow } \\
\text { Condition }\end{array}$ & $\begin{array}{c}\text { Number } \mathbf{x} \\
\text { Duration }\end{array}$ & $\begin{array}{c}\text { Model } \\
\text { Inclination }\end{array}$ \\
\hline \hline 1 & FC-1 & $\begin{array}{c}1 \times 60 \mathrm{~s} \\
3 \times 120 \mathrm{~s}\end{array}$ & 0 \\
\hline 2 & FC-2 & $\begin{array}{c}1 \times 120 \mathrm{~s} \\
2 \times 180 \mathrm{~s}\end{array}$ & 0 \\
\hline 3 & FC-2 & $2 \times 180 \mathrm{~s}$ & $25^{\circ}$ \\
\hline
\end{tabular}

Fig. (2) shows a CCD image of the flow at the exit nozzle impinging on the test model. Fig. (3) shows a picture of the model after the first test, where oxidation due to the high enthalpy flow can be observed. In particular, oxidation appears to occur around the leading edge.

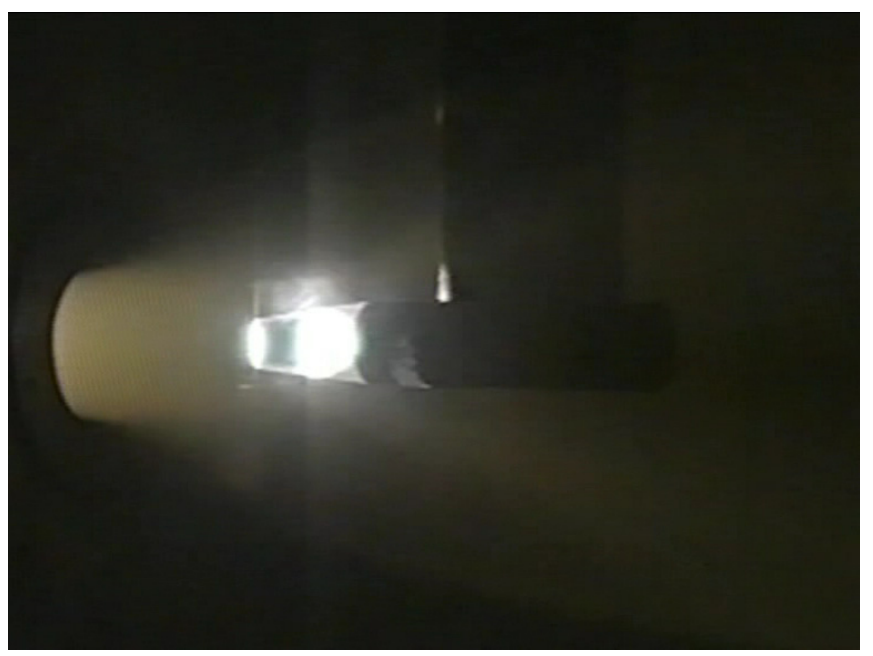

Fig. (2). Test model during the test.

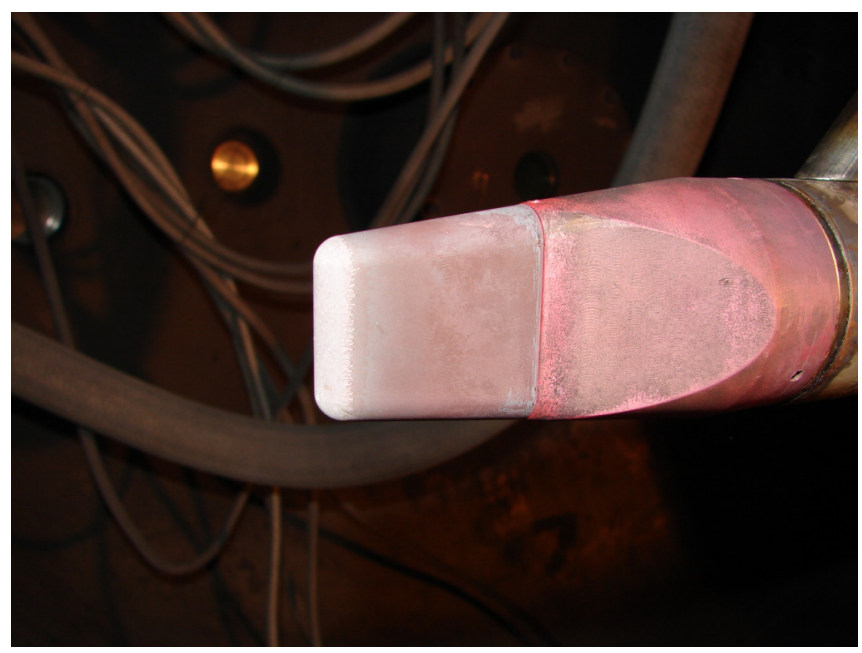

Fig. (3). Test model oxidation after the test.

Figs. (4-6) show the winglet temperature measurements for each graph, corresponding to FC-1, FC-2 and FC-2 $\alpha=25^{\circ}$. Three types of measurements are shown: two-color pyrometer, thermo-camera and thermo-couples. The higher curves (black, red and blue) correspond to the pyrometer thermo-camera and thermocouples measurements in a spot located at $10 \mathrm{~mm}$ distance from the leading edges. The black line, corresponding to the pyrometer, only appears above $1100 \mathrm{~K}$, due to the intrinsically limited temperature range of the pyrometer. The thermo-camera measurement (red line), corresponding to a spectral emissivity (in the spectral band 9-14 $\mu \mathrm{m}$ ) of 0.9 , is in good agreement with the pyrometer values. Temperatures up to $1400 \mathrm{~K}$ are detected in all the test conditions. Steady state seems to be reached, at least on the forward part of the model. The experimental uncertainties shown in these figures are obtained by combining the instrument accuracy, spot location uncertainty and tests repeatability. 


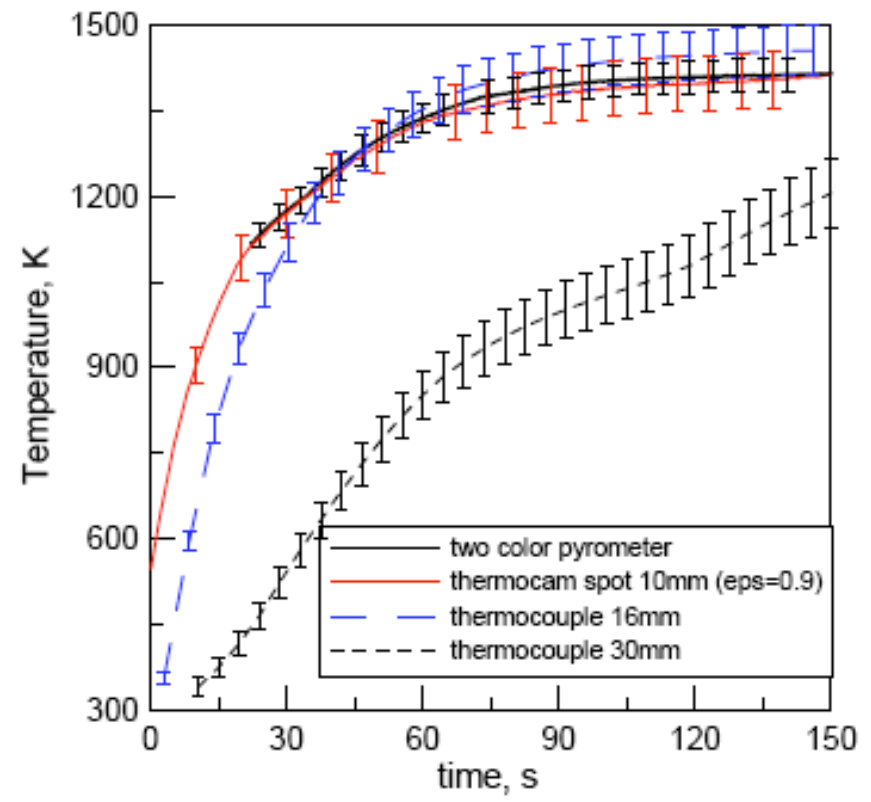

Fig. (4). Temperature measurements at $\mathrm{FC}-1$ conditions ( $\mathrm{Ao} A=0)$.

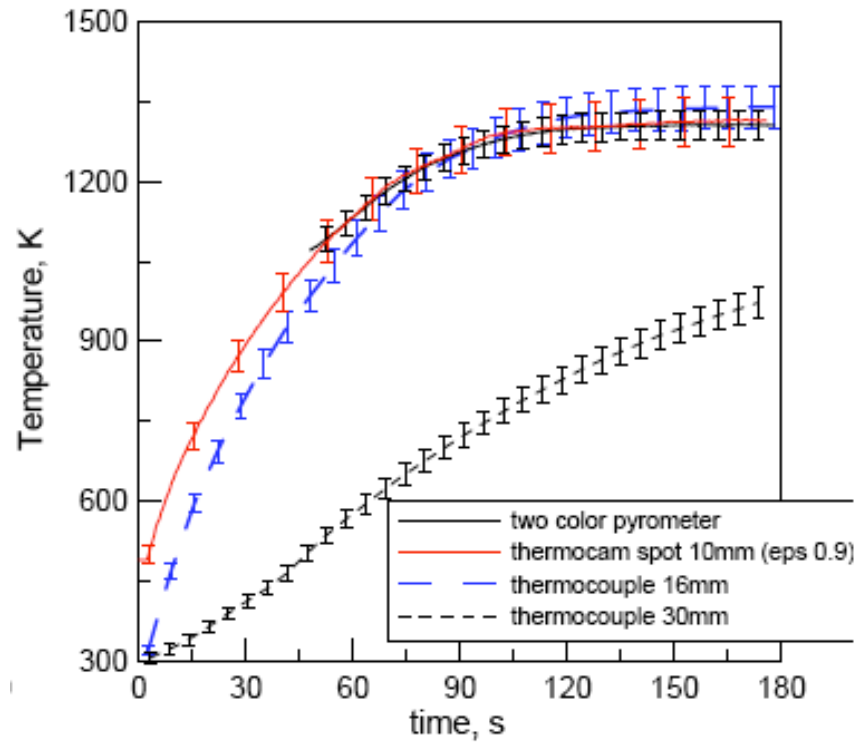

Fig. (5). Temperature measurements at FC-2 conditions (AoA=0).

\section{ARC-JET TESTING OF SMALL SIZE UHTC SPECIMENS}

During the second test campaign small scale hemispherical and conical models, of the same UHTC composition of the rounded wedge, have been exposed to higher heat fluxes enthalpy hypersonic conditions in order to demonstrate the capability of UHTC to resist to very high temperatures $(>2000 \mathrm{~K})$ in oxidizing atmosphere for few minutes. The value of the total enthalpy and of the stagnation point pressures are of the same order of magnitude of those experienced during the test campaign with the rounded wedge but the size of the specimens is very small resulting in higher average heat fluxes and therefore in higher temperatures.

\subsection{Test models}

The conical and hemispherical models are shown in the Fig. (7). The two models have been machined by electroerosion from the same piece. The base diameter is $10 \mathrm{~mm}$ for both the specimens and the full length (specimen plus afterbody) are $10 \mathrm{~mm}$ for hemisphere and $11 \mathrm{~mm}$ for cone. The hemisphere curvature radius is $5 \mathrm{~mm}$ whereas for the cone is $0.5 \mathrm{~mm}$. The specimens are inserted in an alumina support and insulated with Kapyrok sheets.

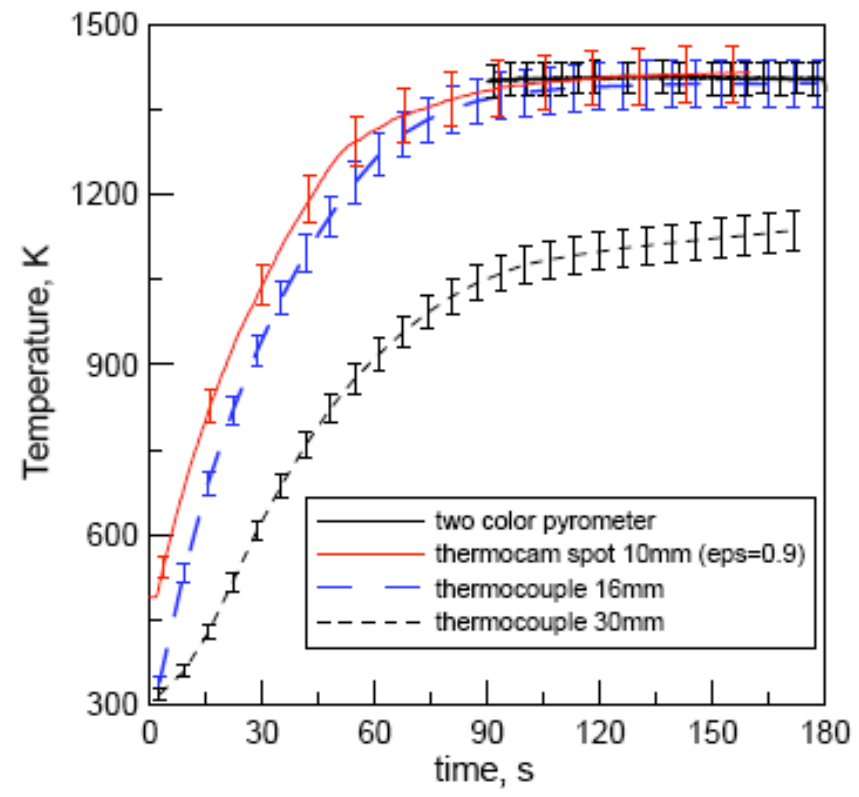

Fig. (6). Temperature measurements at FC-2 conditions $\left(\mathrm{AoA}=25^{\circ}\right)$

A two colour pyrometer (Infratherm ISQ5, Impac Electronic Gmbh, Germany, temperature range $1000{ }^{\circ} \mathrm{C}$ $2000{ }^{\circ} \mathrm{C}$ ) and an infrared thermocamera (Thermacam SC 3000 , FLIR Systems, USA, temperature range $350-2000{ }^{\circ} \mathrm{C}$ ), are used to monitorate the surface temperature.

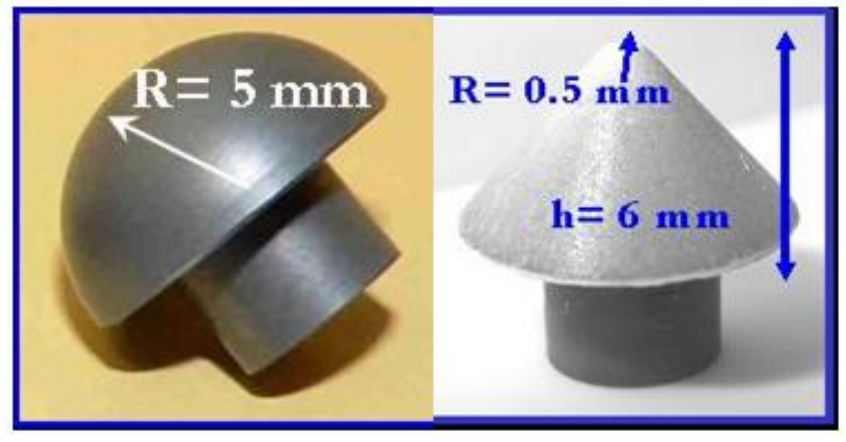

Fig. (7). The hemisphere and the cone.

\subsection{Facility}

The experiments have been carried out with the Small Planetary Entry Simulator (SPES) arc-jet facility available at the University of Naples (Italy). The facility is equipped with a $80 \mathrm{~kW}$ plasma torch that operates with inert gas $(\mathrm{He}, \mathrm{N} 2$, $\mathrm{Ar}$ and their mixtures) at mass flow rates up to $5 \mathrm{~g} / \mathrm{s}$. In order to simulate air composition, $\mathrm{O}_{2}$ can be added by means a swirling jet in the mixing chamber after the torch. The nozzle has a throat diameter of 11, an outer diameter of $22 \mathrm{~mm}$ and the nominal Mach number is $\mathrm{M}=3$. The specimens were located at a distance of $1 \mathrm{~cm}$ from the exit nozzle. 
Two pressure transducers are used at the nozzle exit and in the test chamber, further the stagnation point pressure is provided by an additional third probe. A camcorder give the detailed images of the specimen during the tests. An integrated electronic system allow the control for the gas feed, and the torch current, beyond the arch power and cooling power are monitored. Calculation of the exit nozzle total enthalpy $\mathrm{H}_{0}$ is provided by a energy balance on the system torch-nozzle, by the knowledge of arc power and the cooling power.

The tests have been carried out by fixing the mass flow rate $(\dot{m})$ at $1 \mathrm{~g} / \mathrm{s}$ and increasing the arc current (I) of 50 ampere for each step. Table 3 summarizes the tests conditions. The composition of the tests mixture was $80 \% \mathrm{~N}_{2}$ and $20 \% \mathrm{O}_{2}(\mathrm{wt})$. The stagnation point pressure $\left(\mathrm{p}_{02}\right)$ have been measured by a Pitot probe at $1 \mathrm{~cm}$ from the text nozzle.

Table 3. Small Sized Specimen Test Conditions

\begin{tabular}{|c|c|c|c|c|c|}
\hline & Step1 & Step2 & Step3 & Step4 & Step5 \\
\hline \hline$\dot{m}, \mathrm{~g} / \mathrm{s}$ & 1 & 1 & 1 & 1 & 1 \\
\hline $\mathrm{p}_{02}, \mathrm{mbar}$ & 68 & 74 & 81 & 88 & 95 \\
\hline$\Delta \mathrm{V}, \mathrm{V}$ & 53 & 54 & 56 & 57 & 58 \\
\hline $\mathrm{I}, \mathrm{A}$ & 300 & 350 & 400 & 450 & 500 \\
\hline $\mathrm{H}_{0}, \mathrm{Mj} / \mathrm{kg}$ & 4.5 & 5.5 & 7 & 8.6 & 10 \\
\hline
\end{tabular}

\subsection{Experimental Results}

Fig. (8) shows the pyrometer measurement for the experiments test on the hemispherical and conical. The test on the two specimen in the SPES facility, have been carried out to evaluate the resistance of material in more severe conditions because of the higher temperature expected with respect to that of the wedge discussed in the previous paragraph.

The maximum temperature on the hemisphere was 2050 $\mathrm{K}$ and it was maintained for about $165 \mathrm{~s}$. The maximum temperature of the cone was $2073 \mathrm{~K}$ and it was maintained for about 224s. The models were undamaged after the tests and they show a thin layer of oxides on the surface. The hemisphere show an uniform oxidised layer, while the cone show larger oxidation on the tip and on the base edge, and a very thin layer on the main surface area.

The surface spectral emissivities at $1 \mu \mathrm{m}$ and $9 \mu \mathrm{m}$ have been evaluated by comparison of measurement of the single colour pyrometer $(1 \mu \mathrm{m})$ and the infrared thermocamera $(9 \mu \mathrm{m})$ with the two colours pyrometer measurement (Fig. 9).

\section{NUMERICAL REBUILDING}

\subsection{CFD and Thermal Model}

The numerical model is based on the solution of the Favre-averaged Navier-Stokes equations for a mixture of reacting species in chemical and vibrational non-equilibrium [17]. Species viscosities, thermal conductivity, and mass diffusivities are derived from the kinetic theory of gases [18] as functions of the Lennard-Jones parameters. The solver computes the mixture viscosity and thermal conductivity with the semi-empirical Wilke's rule. The flow is considered as a five species mixture $(\mathrm{N}, \mathrm{O}, \mathrm{N} 2, \mathrm{O} 2, \mathrm{NO})$. From the thermodynamic viewpoint, the system is considered a mixture of reacting ideal gases. In the present computations, the monoatomic species have the translational and rotational modes in equilibrium at the temperature $T$, whereas polyatomic molecules may vibrate at a temperature $T v$ different from $T$. For the chemical reactions, the Park model [19-21] has been included, with the reaction rate constants specified by the Arrhenius law. For the vibration thermal relaxation, the Landau-Teller model was used [22], with Park correction for the high temperatures [23].

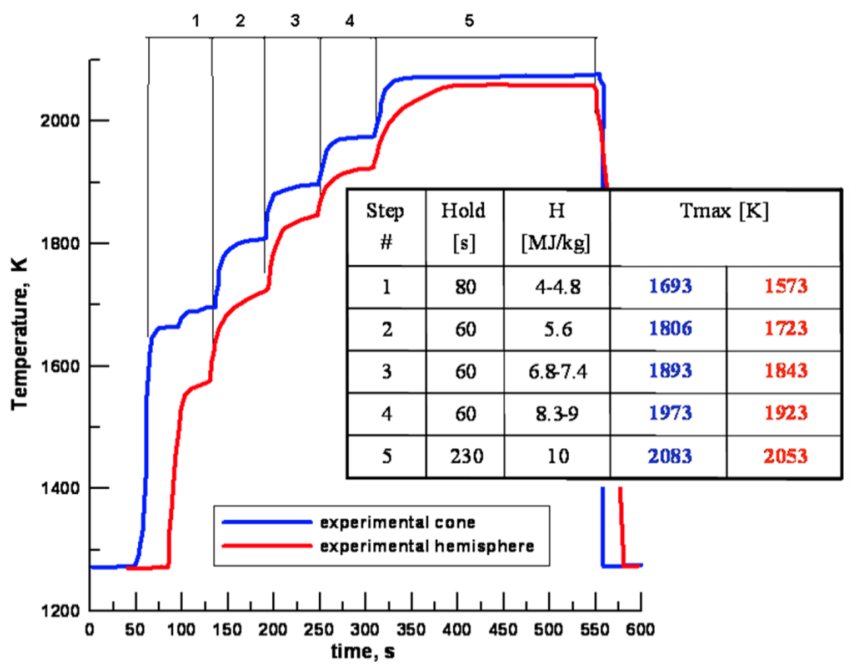

Fig. (8). Temperature evolution of the hemisphere and cone.

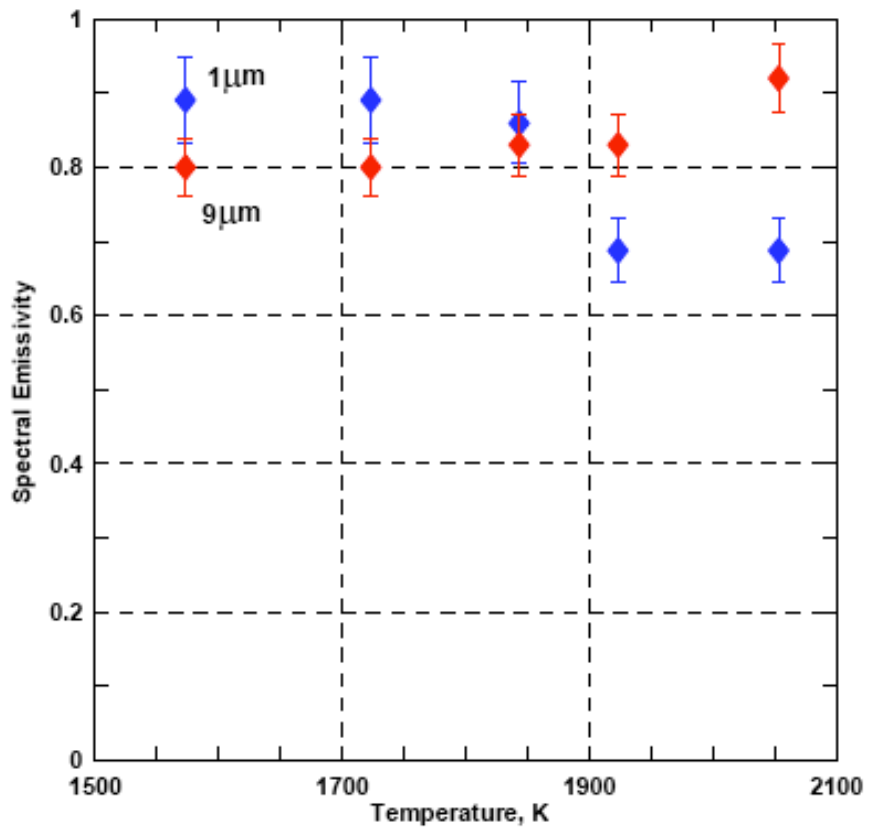

Fig. (9). Spectral emissivity at wavelength of 1 and 9 micron $v s$ temperature.

At solid walls, the no-slip condition is enforced by setting the velocity components to zero. In chemically reacting flows, the mass fractions of the species are dependent variables with their transport equation. Species 
boundary conditions on the wall are assigned according to the behaviour of the solid surface. For a fully catalytic wall, the chemical reactions are catalyzed at an infinite rate and the mass transport at the wall is limited only by the diffusion, at the wall the mass fractions of the dissociated species are equal to zero value. For a non catalytic wall, the diffusive flux of atoms at the wall is set to zero. In addition, a userdefined function has been developed to simulate a wall with a finite value of surface catalycity, according to the following equation [24]:

$\frac{\partial C_{i}}{\partial n}=\frac{C_{i} K_{w}}{D_{i}}$

Eq. 1

where $n$ is the normal coordinate to the wall, $K w$ is the material catalytic constant function of the recombination coefficient $\mathrm{K}_{w}\left(0 \leq \mathrm{K}_{\mathrm{w}} \leq 1\right)$ according to the equation:

$K_{w}=\gamma_{w} \cdot \sqrt{\frac{R_{0} T_{w}}{2 \pi m_{i}}}$

$\mathrm{K}_{\mathrm{w}}$ is a function of both the wall material and of the chemical specie.

The vibration energy at the wall is set considering vibration thermodynamic equilibrium.

Convective fluxes were computed according to Roe's Flux Difference Splitting scheme. Integration of the equations was implicit in time performed, until steady state was achieved, solving the linearised system of equation by the multigrid technique.

The computed surface heat flux distributions have been used to carry out the thermal analysis and to rebuild the thermal evolution of the models under the different test conditions.

The thermal model is based on the solution of the unsteady energy equation in the solid, with the surface heat flux updated at each iteration to account for the energy reemitted radiatively and for the changes in convective heat flux due to changes in surface temperature [25]. For the winglet model surface catalytic recombination factors have been considered in different temperature ranges in order to fit the experimental results. The non catalytic case show good result agreement for the hemispheric and conic model. For the winglet model the temperature measured at the UHTC and copper support interface has been assigned as thermal boundary condition at the back side of specimen.

The winglet model aerodynamic heating has been analyzed assuming the configuration shown in Fig. (10) with a copper support [26].

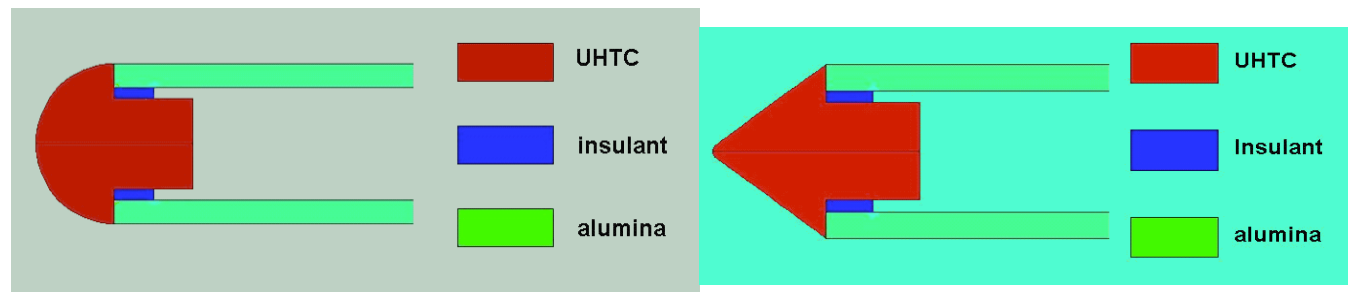

Fig. (12). Hemisphere and cone thermal model.

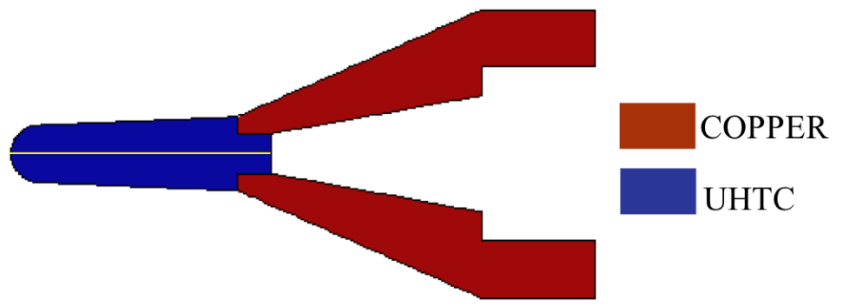

Fig. (10). Rounded wedge thermal model.

The materials thermal properties are reported in Table 4 and Fig. (11).

Table 4. Materials Properties

\begin{tabular}{|c|c|c|c|c|}
\hline & $\mathbf{Z r B}_{2}+\mathbf{1 5 \%}$ SiC & Copper & Alumina & $\begin{array}{c}\text { Thermal } \\
\text { Insulant }\end{array}$ \\
\hline \hline$\rho, \mathrm{kg} / \mathrm{m}^{3}$ & 6000 & 8980 & 3900 & 400 \\
\hline $\mathrm{c}_{\mathrm{p}}, \mathrm{j} / \mathrm{kgK}$ & Variable & 381 & 881 & 469 \\
\hline $\mathrm{K}, \mathrm{W} / \mathrm{mK}$ & 66 & 387 & 30 & 0.15 \\
\hline
\end{tabular}

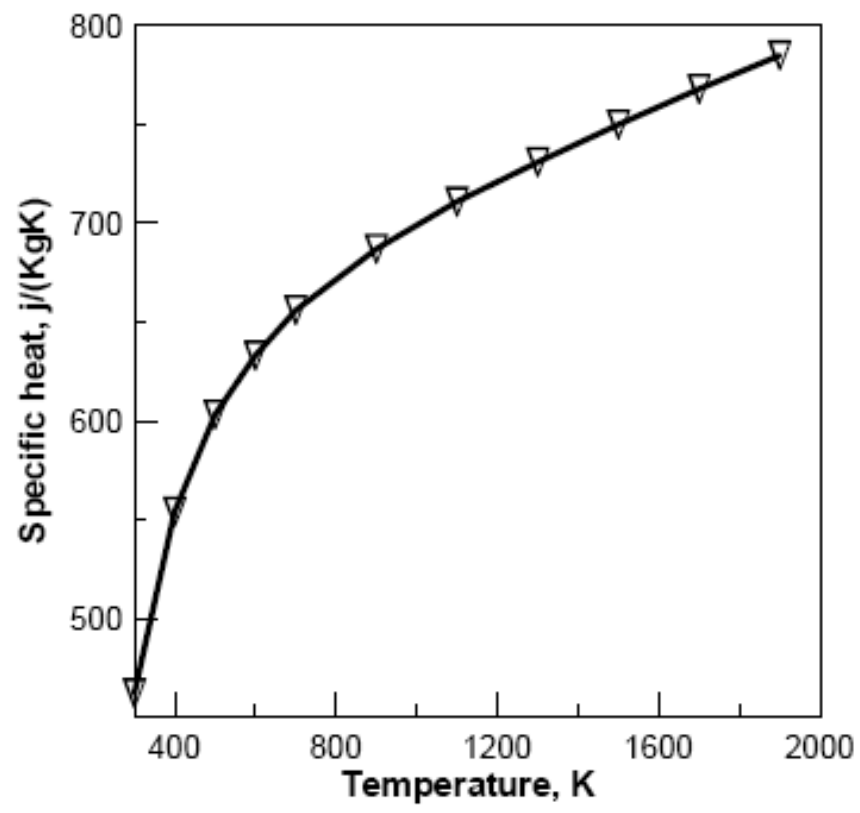

Fig. (11). UHTC Specific heat function of temperature.

The hemisphere and cone model are shown by Fig. (12).

\subsection{Rounded Wedge}

Axis-symmetric numerical computation of the nozzle flow have been carried out in order to identify the flow conditions around the model. Fig. (13) shows the Mach number contour for 
(a)

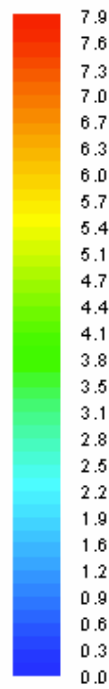

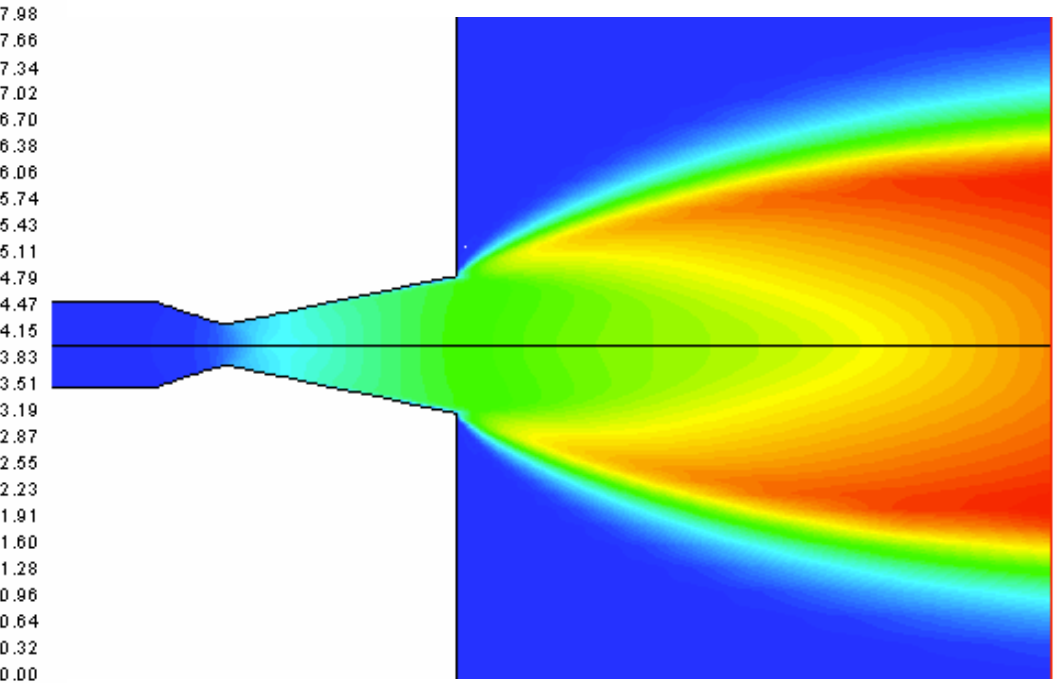

(b)

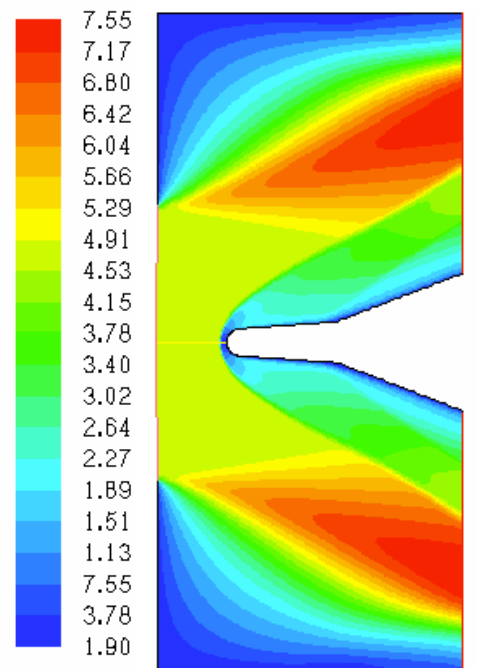

Fig. (13). Mach number contour; (a) nozzle and test chamber; (b) around the model.

the FC-2 test case both for the nozzle and around the model. The results show a flow expansion at the exit nozzle, as can be also observed in the CCD image of Fig. (2), resulting in larger Mach number than nominal at the model position.

Table 5 reports the main flow parameters at the model position for the two test case as static and total pressure ( $p$ and $\mathrm{P}_{0}$ ), velocity $(\mathrm{V})$ and Mach number $(\mathrm{M})$, kinetic temperature and vibrational temperature for diatomic molecules $\left(\mathrm{T}_{\mathrm{vN} 2}, \mathrm{~T}_{\mathrm{vO} 2}\right.$ and $\left.\mathrm{T}_{\mathrm{vNO}}\right)$, mixture density $(\rho)$ and species mass fraction $\left(\mathrm{y}_{\mathrm{i}}\right)$. These condition have been used as input for the 2-D computation of the aerothermal field around the model. Fig. (14) shows the pressure distributions for FC2 case at 0 and $10^{\circ}$ of angle of attach; as can be noted by Fig. (14) the pressure distributions are not affected by the catalytic properties. Very similar pressure distributions have been obtained also for FC1 condition.

Table 5. Flow Conditions at Model Location

\begin{tabular}{|c|c|c|}
\hline & FC1 & FC2 \\
\hline \hline $\mathrm{p}, \mathrm{Pa}$ & 222 & 223 \\
\hline $\mathrm{P}_{0}, \mathrm{~Pa}$ & $1.07 \cdot 10^{5}$ & $1.05 \cdot 10^{5}$ \\
\hline $\mathrm{V}, \mathrm{m} / \mathrm{s}$ & 3130 & 2570 \\
\hline $\mathrm{M}$ & 5.09 & 4.99 \\
\hline $\mathrm{T}, \mathrm{K}$ & 753 & 587 \\
\hline $\mathrm{Tv}_{\mathrm{N} 2}, \mathrm{~K}$ & 4460 & 3410 \\
\hline $\mathrm{Tv}_{\mathrm{O} 2}, \mathrm{~K}$ & 4700 & 3260 \\
\hline $\mathrm{Tv}_{\mathrm{NO}}, \mathrm{K}$ & 4670 & 3440 \\
\hline$\rho, \mathrm{kg} / \mathrm{m}^{3}$ & $8.48 \mathrm{e}-4$ & $1.19 \mathrm{e}-3$ \\
\hline $\mathrm{y}_{\mathrm{O}}$ & 0.225 & 0.114 \\
\hline $\mathrm{y}_{\mathrm{O} 2}$ & $4.01 \mathrm{e}-3$ & $9.34 \mathrm{e}-2$ \\
\hline $\mathrm{y}_{\mathrm{N} 2}$ & 0.769 & 0.75 \\
\hline $\mathrm{y}_{\mathrm{NO}}$ & $2.37 \mathrm{e}-3$ & $4.33 \mathrm{e}-2$ \\
\hline
\end{tabular}

The surface heat flux distributions for FC-2 at an angle of attack of 0 and $25^{\circ}$ cases are shown in Fig. (15) for a fully catalytic and non catalytic wall. The results highlight the concept of the boundary layer thermal protection [21], in fact the surface heat flux on the stagnation point is of the order of $2 \mathrm{MW} / \mathrm{m}^{2}$, but it quickly decreases of one order of magnitude along the body due to the increasing thickness of the boundary layer.

The rounded wedge thermal analysis results are shown in Figs. $(16,17)$. The figures show the numerical experimental correlations for the different test conditions, the experimental values refer to the centreline of the wedge taken by infrared image. The correlation is possible with a variable catalytic recombination factor with temperature as shown in Fig. (18), where typical values of surface catalytic recombination for the $\mathrm{ZrB}_{2}$ and for other materials are reported for comparison. In this case a total emissivity of 0.9 allows to fit the experimental data.

As expected, the high thermal conductivity of the UHTC give allows a strong decrease of the maximum tip temperature and to an increase of the temperature downstream of the stagnation point (blue curves and experimental results) respect to the local radiative equilibrium condition (red curve). Instead, the assumption of local radiative equilibrium wall over-estimates the stagnation point temperature and underestimates the surface temperature distribution downstream the leading edge. This effect is larger when TPS materials are characterized by high thermal conductivity.

Considering the test condition at angle of attack the windside is exposed to higher heat fluxes than the leeside and therefore "heat" flows conductively across the specimen between windside and leeside, levelling the temperatures, reducing the temperature on the windside and increasing the leeside level (Fig. 17). The leeside of the specimen has a greater amount of energy radiated to the environment. Therefore at the global radiative equilibrium condition the 
(a)

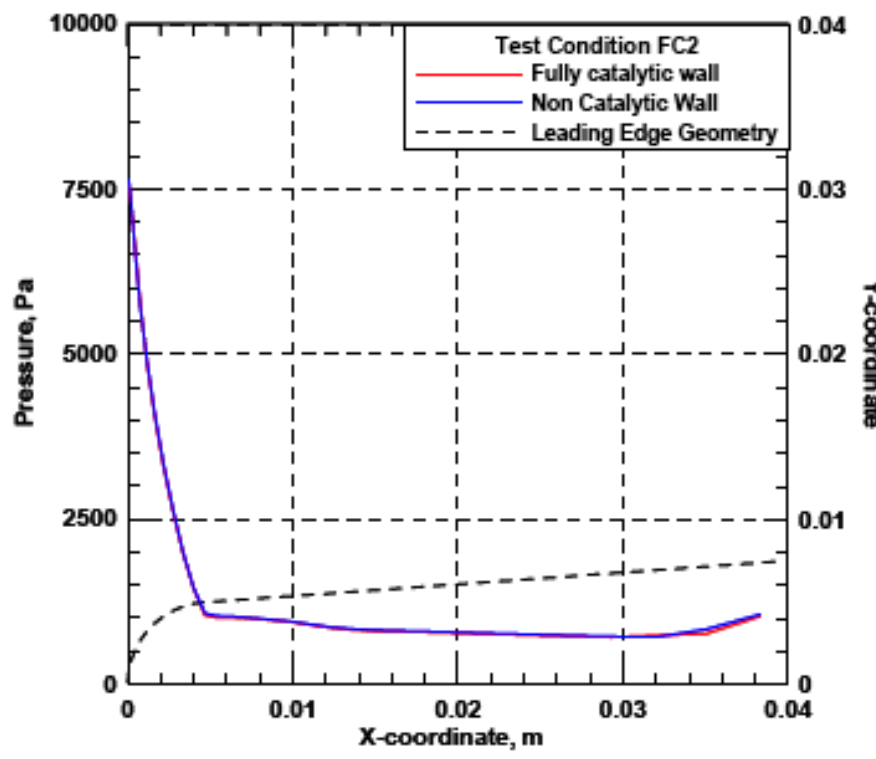

(b)

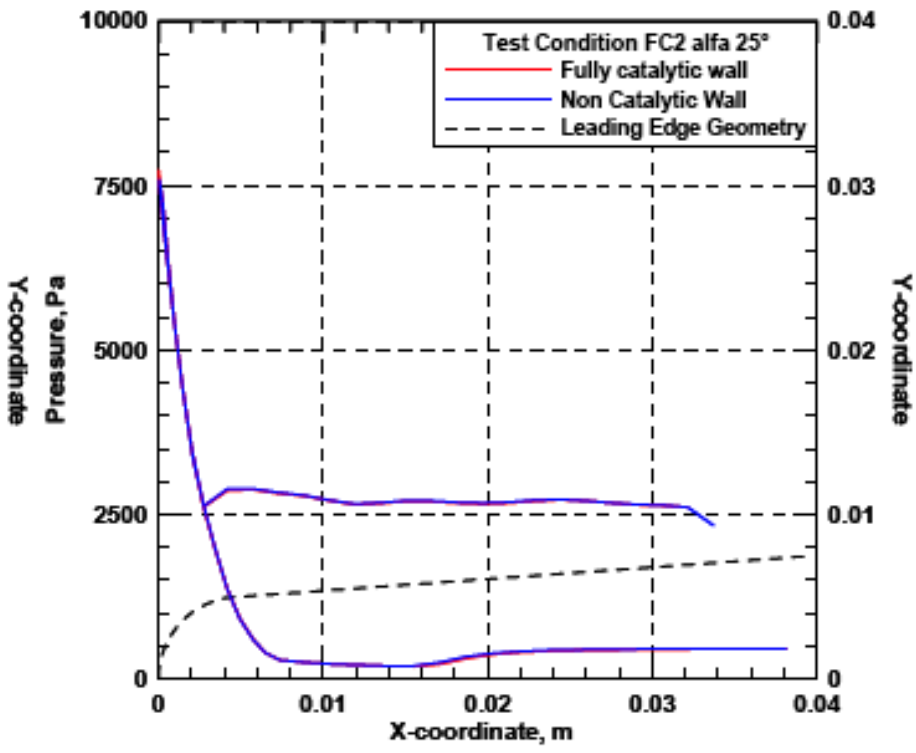

Fig. (14). Pressure distribution along the body for fully and non catalytic wall for FC-2 test condition at $\mathrm{AoA}=0$ (a) and $\mathrm{AoA}=25^{\circ}(\mathbf{b})$.

(a)

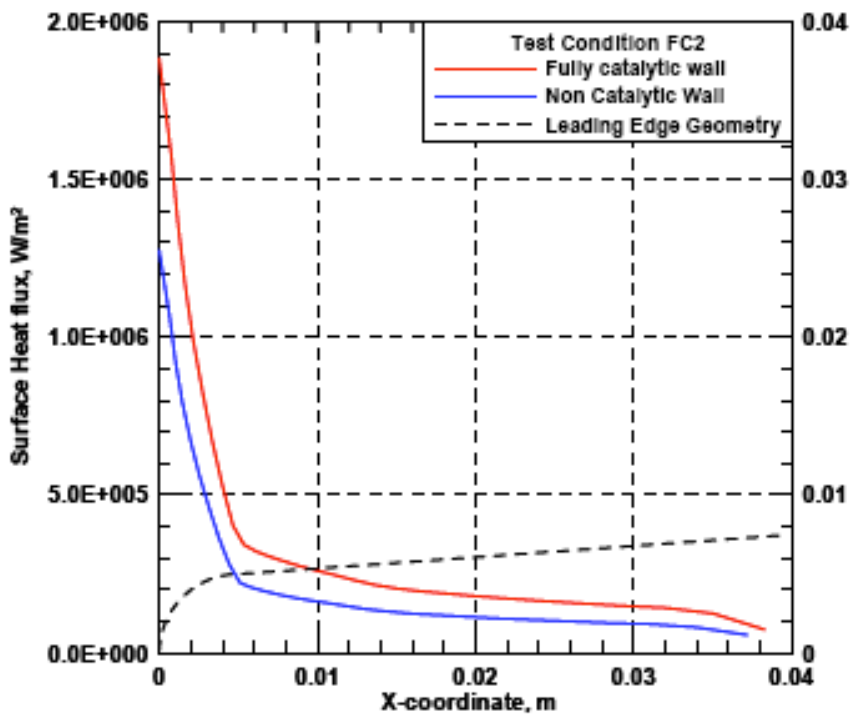

(b)

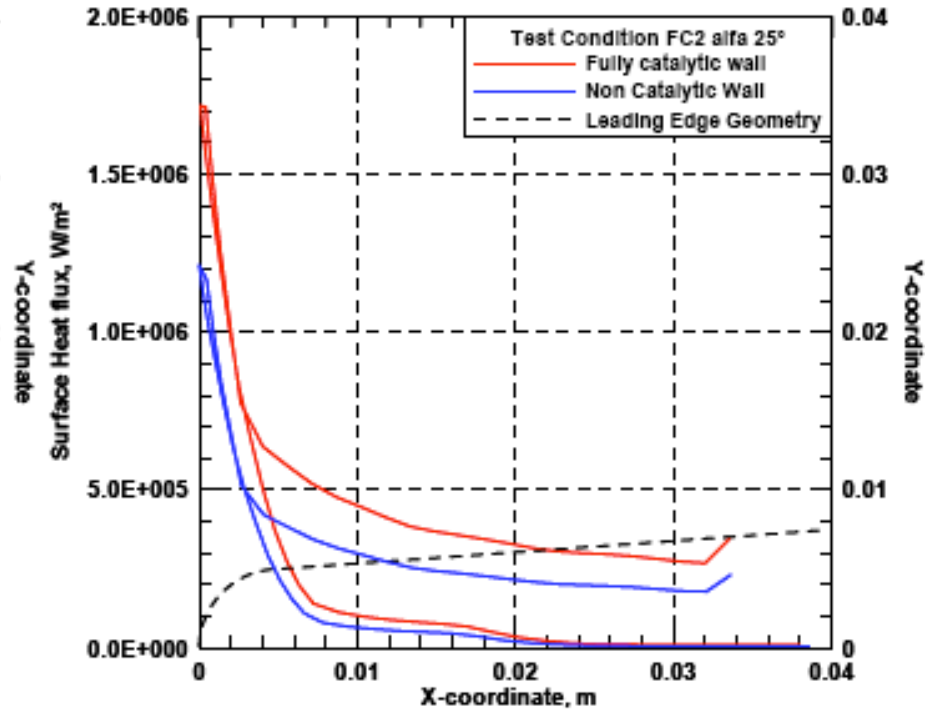

Fig. (15). Surface heat flux distribution along the body for fully and non catalytic wall for $\mathrm{FC}-2$ test condition at $\mathrm{AoA}=0$ and $\mathrm{AoA}=25^{\circ}$.

surface temperature for the case at an angle of attack of $25^{\circ}$ is close that of the case at 0 angle of attack case.

\subsection{Small Sized Specimens}

Also in this case, as for the previous one, numerical computation of the nozzle flow have been carried out in order to identify the flow conditions around the model. Fig. (19) shows the Mach number contour for the highest enthalpy case. Table 6 reports the main flow parameters at the model position.

Fig. (20) shows the leading edge pressure and surface heat fluxes values versus the normalised specimen length of hemisphere and cone for the torch power of $28 \mathrm{Kw}$ case. The stagnation point pressure of the cone results slightly larger than hemisphere and the stagnation point heat flux of the cone results again larger than expected also taking into account the scaling law with the inverse of curvature radius. These differences could be justified by order of magnitude analyses of Knudsen number considering the nose radius as reference length. The Knudsen number for the cone $(0.2<\mathrm{Kn}<1)$ is in the transition regime therefore the Navier Stokes equations used in the CFD code are still valid but the pressure and the wall heat flux results larger than the expected values [27].

The Fig. (21) shows the computed wall shear stress distributions superimposed on the model pictures after tests. The distributions are quite different and this can be one of the causes of the different oxidation behavior as described in paragraph 3.3. 
(a)

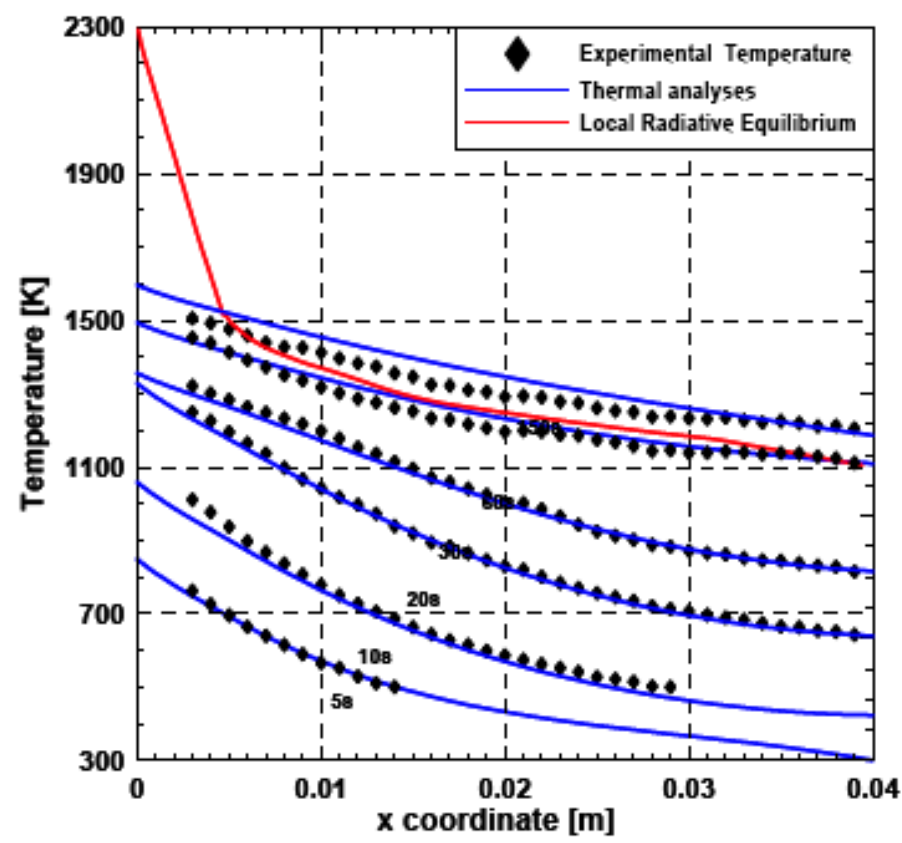

(b)

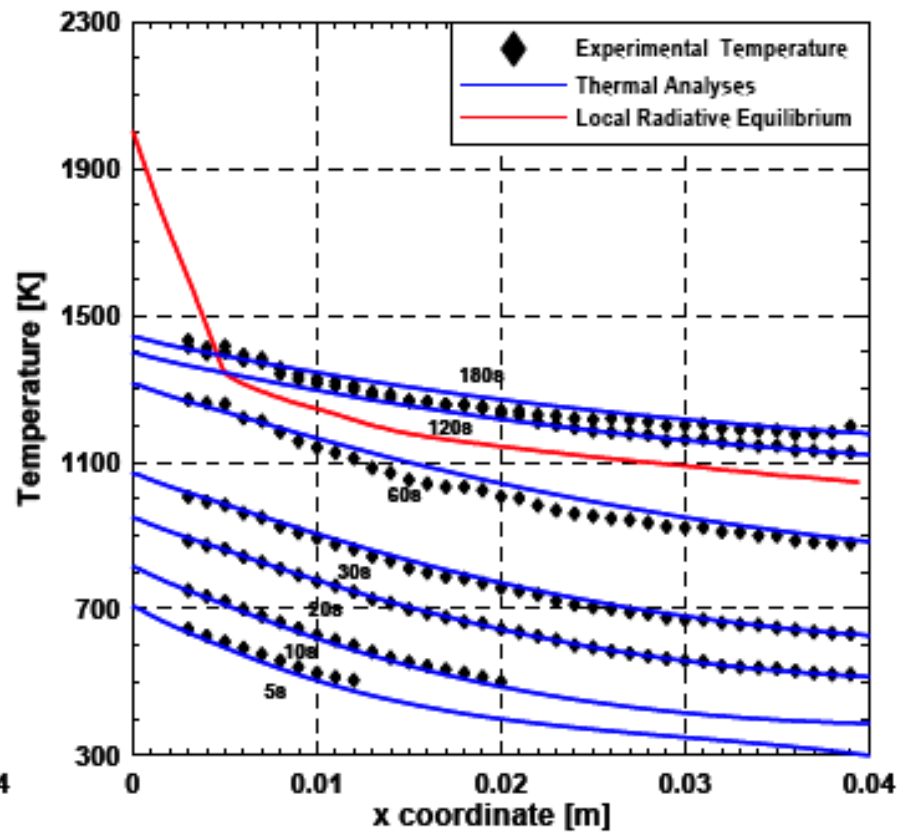

Fig. (16). Temperature evolution on centreline for the test conditions FC1 (a) and FC2 (b) at $\alpha=0$.

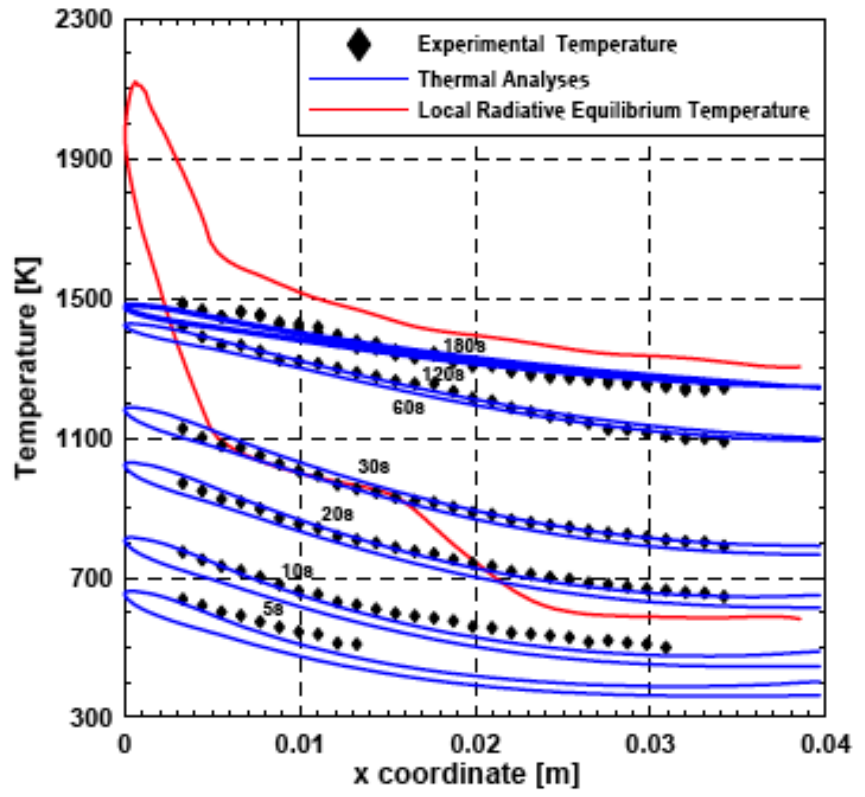

Fig. (17). Temperature evolution on centreline for the test condition FC2 at $\alpha=25^{\circ}$.

A transient thermal analyses has been carried out for the 22 and $28 \mathrm{KW}$ cases for the nose and the hemisphere just to compare the steady state temperature value with the experimental ones. Fig. (22) shows the evolution of the computed temperatures and the steady state experimental points; the cone heating is faster respect the hemisphere due to the smaller specimen volume (and mass). The steady state temperature does not differ too much because the average the surface heat flux, the emissivity and the sample's thermal conductivity are very similar for both the models.

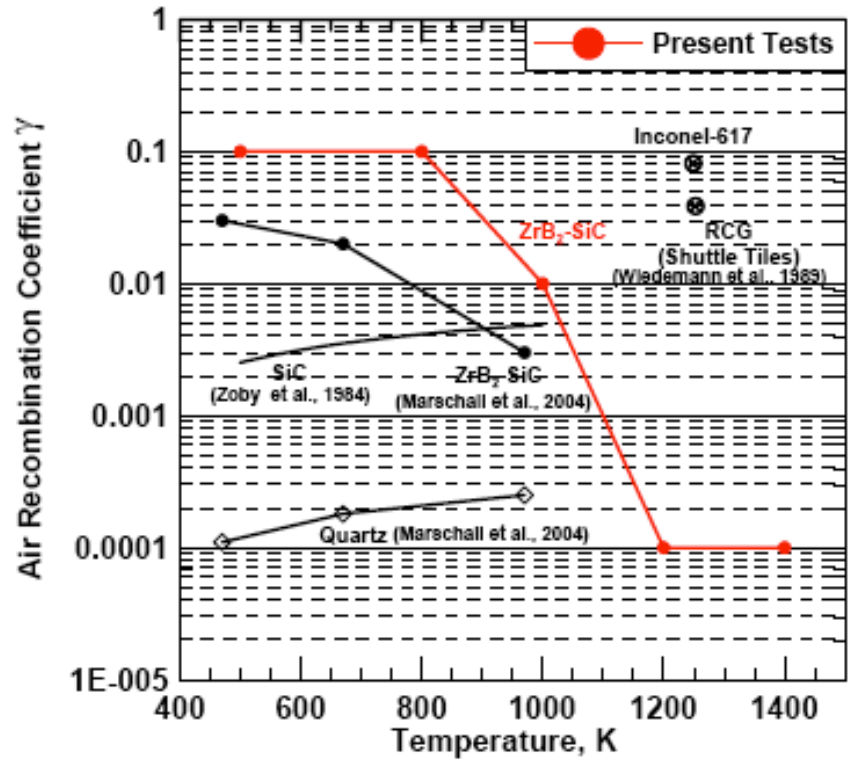

Fig. (18). Surface catalycity evaluation on $\mathrm{ZrB} 2$ test models and comparison with literature data (Marchall et al. results refer to side arm reactor tests; the others refer to arc jet tests).

For these cases, considering the Fig. (16), the non catalytic wall conditions have been imposed at the model surfaces due to the high temperature values (larger than $\left.1200^{\circ} \mathrm{C}\right)$.

The Tables 7 and $\mathbf{8}$ report the numerical averaged temperature in a spot of $3 \mathrm{~mm}$ of diameter in the same area targeted by the pyrometer $\left(\mathrm{T}_{\text {spot }}\right)$.

The numerical results are close to the experimental values considering zero catalytic efficiency and an emissivity 
(a)

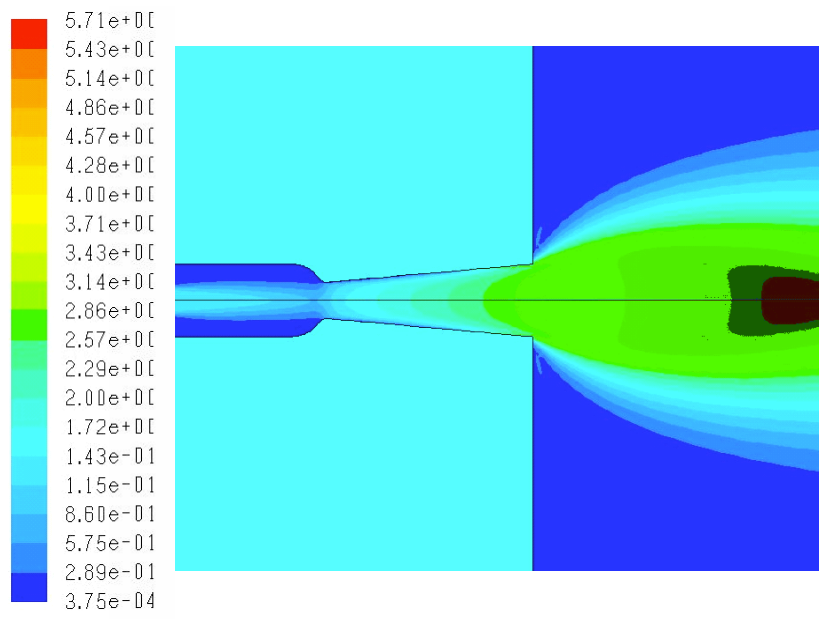

(b)

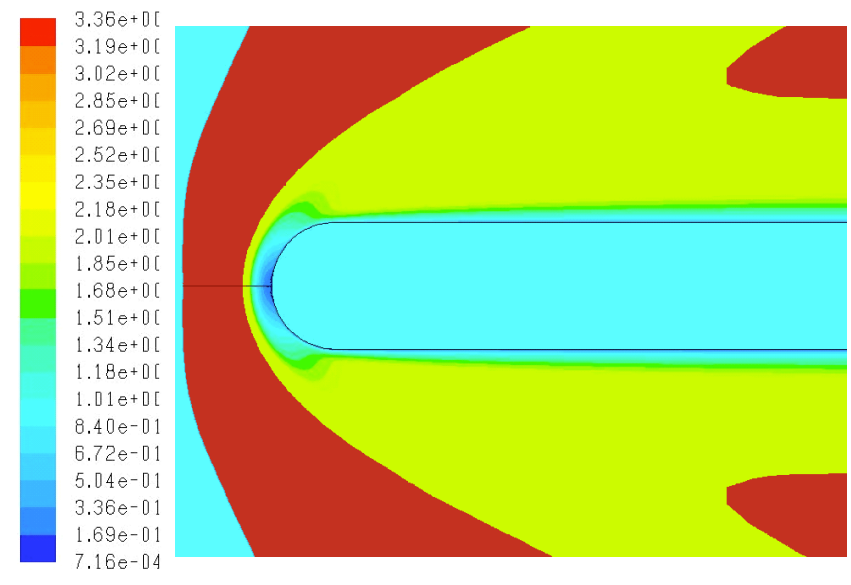

Fig. (19). Mach number contour. (a) Nozzle and test chamber; (b) around the model.
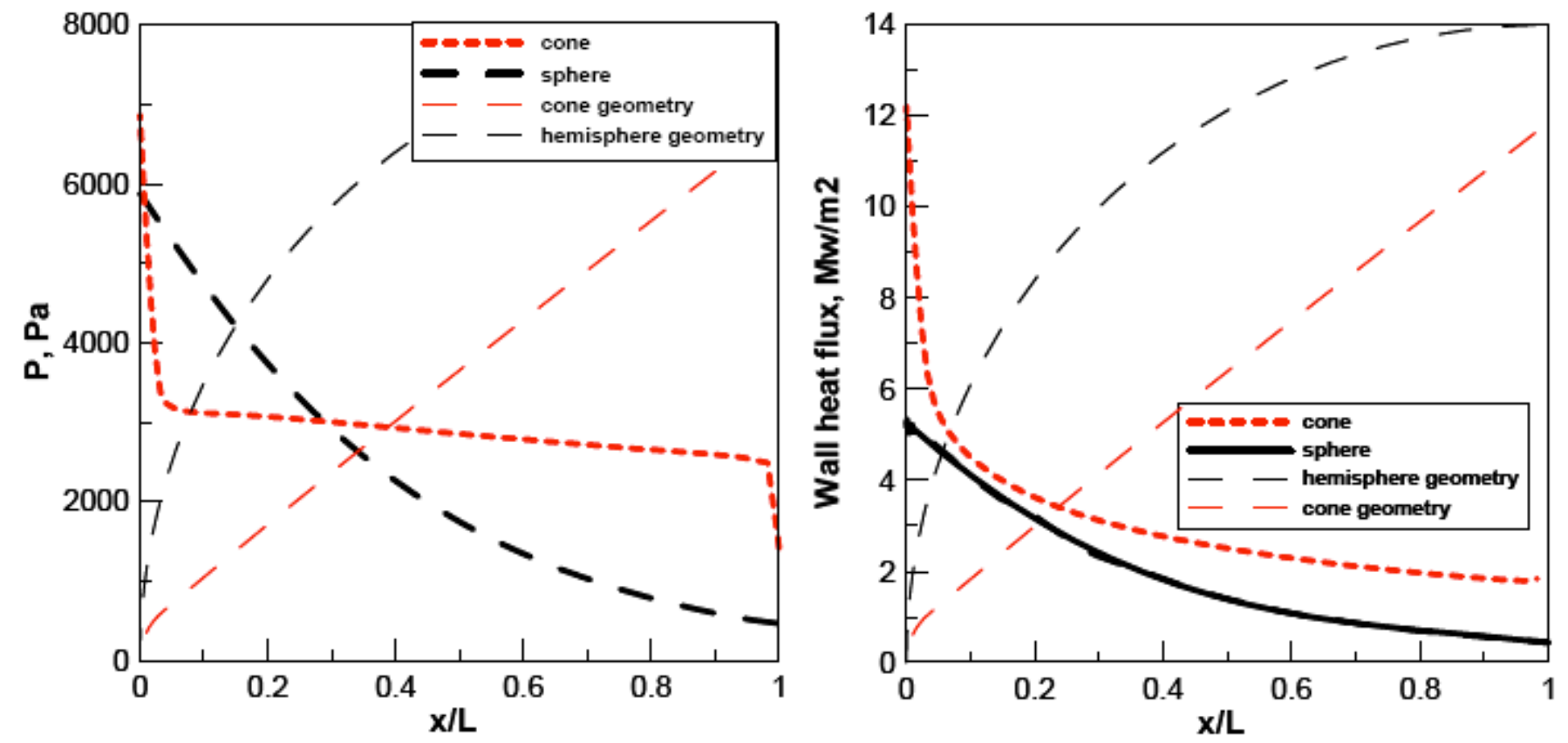

(a)

(b)

Fig. (20). Pressure (a) and surface heat flux (b) distribution along the bodies for non catalytic wall for the torch power of $28 \mathrm{~kW}$ case.

equal to 0.6 , which is close to the spectral emissivity at 1 micron wavelength evaluated by pyrometer measurements.

In comparison to the experiments reported in $[14,15]$, corresponding to high enthalpy subsonic flow conditions (atmospheric pressure discharge) the surface emissivity is relatively lower ( 0.7 at the highest temperature in the present cases, and 0.9 in the subsonic tests). These results show that the surface oxidation is affected not only by the total enthalpy level of the flow but also by the peculiar flow behaviour and that in hypersonic conditions the material response can be greatly different. One of the consequences of the lower surface emissivity is that the equilibrium temperature achieved by the specimens is of the same order $(2000 \mathrm{~K})$ of that achieved in the subsonic flow tests reported in $[14,15]$ even though the total enthalpy level in the present cases is relatively lower $(10 \mathrm{Mj} / \mathrm{kg})$ than that in high pressure tests (up to $20 \mathrm{Mj} / \mathrm{kg}$ ).

\section{CONCLUSIONS}

Arc jet experiments at hypersonic conditions with three different UHTC models have been carried out in order to analyze the aerothermal environment and to characterize the material behaviour. The temperature measurements have been performed using pyrometers, an IR thermocamera and thermocouples. The UHTC $\mathrm{ZrB}_{2}$ based has been tested for several minutes to temperatures up to $2050 \mathrm{~K}$ showing a good resistance in that extreme conditions. It is important to point out that the flow conditions and the sharpness of the models are similar but the larger model (rounded wedge) configuration is such that the heat flux distributions (peaking 

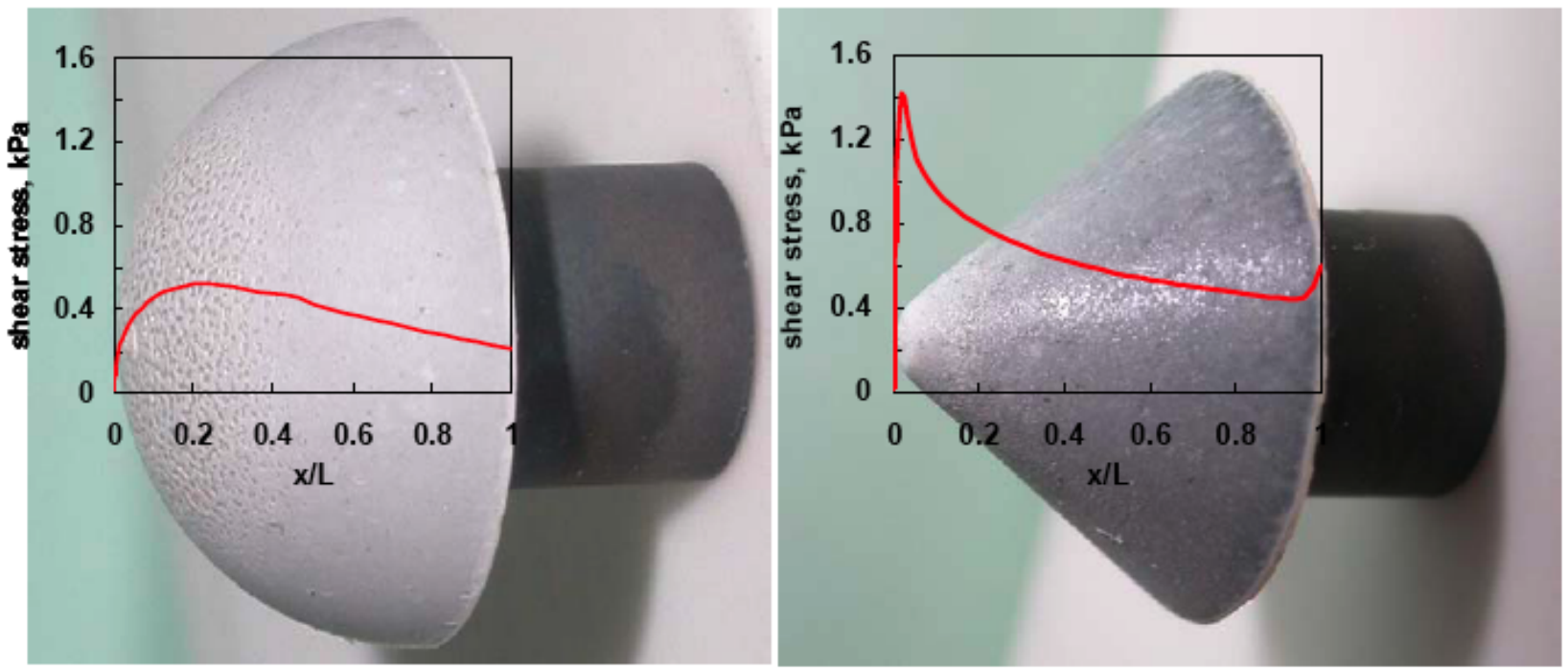

Fig. (21). Surface shear stress along the hemisphere and cone for non catalytic wall for $28 \mathrm{~kW}$ test condition.

Table 6. Flow Conditions at Model Location

\begin{tabular}{|c|c|}
\hline & Step 5 \\
\hline \hline $\mathrm{p}, \mathrm{Pa}$ & 223 \\
\hline $\mathrm{P}_{0}, \mathrm{~Pa}$ & 20640 \\
\hline $\mathrm{V}, \mathrm{m} / \mathrm{s}$ & 3233 \\
\hline $\mathrm{M}$ & 3.35 \\
\hline $\mathrm{T}, \mathrm{K}$ & 1938 \\
\hline $\mathrm{Tv}_{\mathrm{N} 2}, \mathrm{~K}$ & 8230 \\
\hline $\mathrm{Tv}_{\mathrm{O} 2}, \mathrm{~K}$ & 3264 \\
\hline $\mathrm{Tv}_{\mathrm{NO}}, \mathrm{K}$ & 464 \\
\hline$\rho_{\mathrm{kg} / \mathrm{m}^{3}}$ & $3.85 \mathrm{e}-4$ \\
\hline $\mathrm{y}_{\mathrm{O}}$ & 0.061 \\
\hline $\mathrm{y}_{\mathrm{O} 2}$ & 0.065 \\
\hline $\mathrm{y}_{\mathrm{N} 2}$ & 0.735 \\
\hline $\mathrm{y}_{\mathrm{NO}}$ & $4.33 \mathrm{e}-3$ \\
\hline
\end{tabular}

at the leading edge and strongly decreases downstream) results in a lower average surface heat flux and therefore (also due to the relatively high thermal conductivity) to smaller equilibrium temperature than smaller specimens. Indeed the maximum temperature achieved during the test campaign on the rounded wedge is in the order of $1500 \mathrm{~K}$, where at similar conditions the smalls sized hemispherical and conical specimen exhibits equilibrium temperature of 2000 K. Numerical-experimental correlations carried out by a CFD code show a good agreement with proper modelling of the surface catalytic behaviour resulting in a decrease of catalytic efficiency from relatively high value at low temperatures (up to a non catalytic behaviour. As expected the higher temperature achieved than in the rounded wedge tests and the lower pressure than in the past subsonic arc-jet tests increase the oxidation phenomena. The change in surface composition can justify the lower value of the surface emissivity estimated in the present work respect to previous subsonic experiments.

Table 7.

\begin{tabular}{|c|c|c|c|}
\hline Arc Power $[\mathbf{K w}]$ & $\mathbf{H}_{\mathbf{0}}[\mathbf{M j} / \mathbf{K g}]$ & Tspot $[\mathbf{K}]$ & Texp $[\mathbf{K}]$ \\
\hline \hline 28 & 10.3 & 2031 & 2083 \\
\hline 22 & 7.3 & 1819 & 1893 \\
\hline
\end{tabular}

Table 8.

\begin{tabular}{|c|c|c|c|}
\hline Arc Power $[\mathbf{K w}]$ & $\mathbf{H}_{\mathbf{0}}[\mathbf{M j} / \mathbf{K g}]$ & Tspot $[\mathbf{K}]$ & Texp [K] \\
\hline \hline 28 & 10.3 & 2089 & 2053 \\
\hline 22 & 7.3 & 1880 & 1843 \\
\hline
\end{tabular}

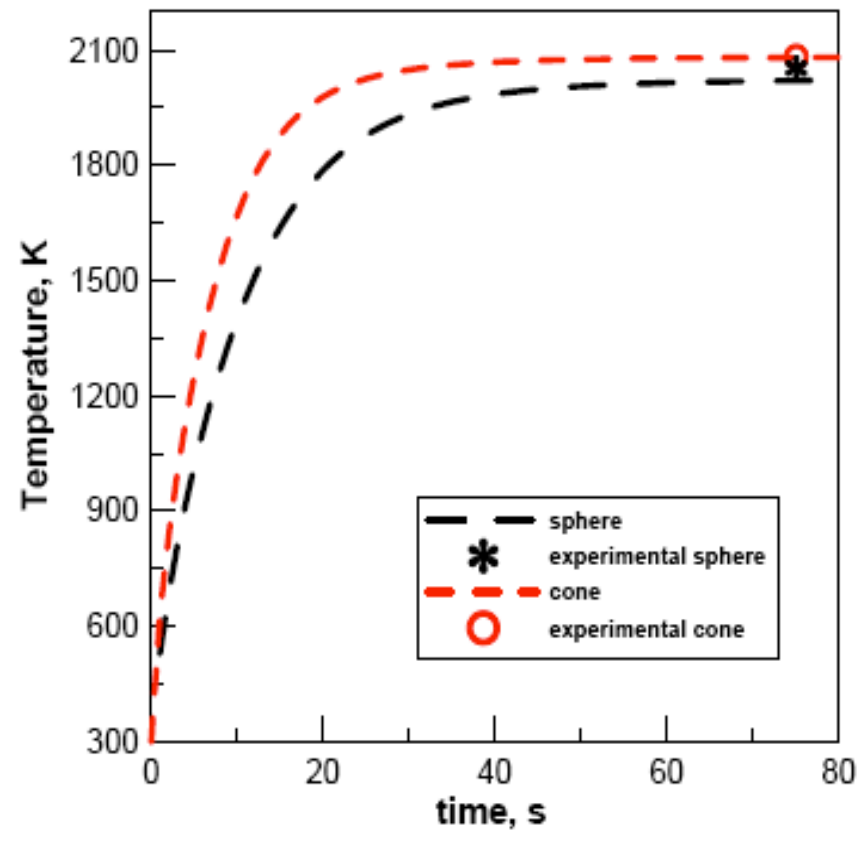

Fig. (22). Temperature evolution on hemisphere and on cone. 


\section{REFERENCES}

[1] R. Monti, G. Pezzella, "Low Risk Reentry Vehicle", $12^{\text {th }}$ AIAA International Space Planes and Hypersonic Systems and Technologies, 15-19 December 2003, Norfolk, Virginia.

[2] R. Monti, D. M. Paterna, "A low risk reentry: looking backward to step forward", Aerospace Sci. Technol., vol. 10, no. 2, pp. 156-167, 2006.

[3] R. Janowski, M. Tauche, M. Scheper, R. Monti, R. Savino, "Spaceplane: a New Way for Atmospheric Reentry", In Proceedings of the 1st Inter-National ARA Days, Atmospheric Reentry Systems, Missions and Vehicles, Session 15-System Design, 2006.

[4] R. Monti, R. Janovsky, R. Savino, M. De Stefano Fumo, "Exploiting Lift Force in Reentries from Exploration Missions", DGLR International Symposium "To Moon and beyond", 14 - 16 March, 2007, Bremen, Germany.

[5] I. E. Campbell, E. M. Sherwood, High-Temperature Materials and Technology, New York: Wiley 1967.

[6] E. Wuchina, M. Opeka, S. Causey, J. Spain, A. Cull, J. Routbort, F. Guitierrez-Mora, "Designing for utrahigh-temperature applications: the mechanical and thermal properties of $\mathrm{HfB} 2, \mathrm{HfCx}, \mathrm{HfNx}$ and VंHf(N))", J. Mater Sci., vol. 39, pp. 5939-49, 2004.

[7] E. V. Clougherty, L. Kaufman, "Investigation of boride compounds for very high temperature applications", ManLabs, Inc., Cambridge, MA, Air Force Technical Documentary Report No. RTD-TDR-63-4096, 1963

[8] S. R. Levine, E. Opila, M. Halbig, J. Kiser, M. Singh, "Evaluation of ultra-high temperature ceramics for aeropropulsion use", J. Eur. Ceram. Soc., vol. 22, no. 14-15, pp. 2757-67, 2002.

[9] W. G. Fahrenholtz, G. E. Hilmas, "NSF-AFOSR Joint Workshop on Future Ultra-High Temperature Materials", National Science Foundation Workshop, Arlington, VA, 13-14 January 2004.

[10] R. Monti, M. De Stefano Fumo, R. Savino, "Thermal shielding of a reentry vehicle by ultra high temperature ceramic materials", $J$. Thermophys, Heat Transf., vol. 20, no. 3, pp. 500-506, 2006.

[11] R. Monti, R. Savino, D. Paterna, M. De Stefano Fumo, "The Boundary Layer Thermal Protection System: an Advanced Concept for Protecting Hot Structures During Re-entry, Thermal Protection Systems and Hot Structures", Proceedings of the 5th European Workshop held 17-19 May, 2006 at ESTEC, Fletcher. K, Ed. Noordwijk, The Netherlands, ESA SP-631, European Space Agency, Published on CDROM, p. 33.1, 2006.

[12] F. Monteverde, "Beneficial effects of an ultra-fine $\alpha$-SiC incorporation on the sinterability and mechanical properties of ZrB ${ }_{2}$, Appl. Phys. A., vol. 82, pp. 329-337, 2006

[13] L. Silvestroni, and Sciti, D., "Effects of MoSi2 additions on the properties of $\mathrm{Hf}-$ and $\mathrm{Zr}-\mathrm{B} 2$ composites produced by pressureless sintering," Scr. Mater., vol. 57, pp. 165-168, 2007.
[14] F. Monteverde, and R. Savino, "Stability of ultra-high-temperature $\mathrm{ZrB} 2-\mathrm{SiC}$ ceramics under simulated atmospheric re-entry conditions", J. Eur. Ceram. Soc., vol. 27, pp. 4797-805, 2007.

[15] R. Savino, M. De Stefano Fumo, L. Silvestroni, D. Sciti, "Arc-jet testing on HfB2 and HfC-based ultra-high temperature ceramic materials", J. Eur. Ceram. Soc., vol. 28, pp. 1899-1907, 2008.

[16] A. Esser, Guelhan, "Flow field characterisation of DLR's archeated facilities L2K and L3K”, ESA, SP-426, pp. 545-551, 1998.

[17] C. Park, R. L. Jaffe, H. Partridge, "Chemical-kinetic Parameters of Hyperbolic Earth Entry", J. Thermophys. Heat Transf., vol. 15, pp. 76-90, 2001

[18] J. O. Hirscfelder, C. F. Curtiss, R. B. Bird, Molecular Theory of Gases and Liquids, Wiley: New York, 1954, pp. 75-106.

[19] C. Park, "Review of chemical kinetics problems for future NASA mission, Part 1: earth entries", J. Thermophys. Heat Transf., vol. 7 , no. 3, pp. 385-398, 1993.

[20] C. Park, "Review of chemical kinetics problems for future NASA missions", AIAA J. Thermophys. Heat Transf., vol. 7, no. 33, pp. 385-398, 1993.

[21] C. Park, J. T. Howe, R. L. Jaffe, G. V. Chandler, "Review of chemical kinetic problems of future NASA missions. II: mars entries", J. Thermophys. Heat Transf., vol. 8, no.1, pp. 9-23, 1994.

[22] R. C. Millikan, D. R. White, "Systematics of vibrational relaxation", J. Chem. Phys., vol. 39, no. 12, pp. 3209-3213, 1963.

[23] C. Park, Nonequilibrium Hypersonic Aerothermodynamics, New York: John Wiley \& Sons, 1990

[24] O. N. Suslov, G. A Tirskiy, "The kinetics of the recombination of nitrogen atoms on high temperature reusable surface insulation in hypersonic thermo-chemical non-equilibrium flow, aerothermodynamics for space vehicles," Proceedings of the 2nd European Symposium held in ESTEC, Noordwijk, The Netherlands, 21-25 November, 1994, J. J. Hunt, Ed., European Space Agency, Paris, 1995, p. 413

[25] R. Savino, M. De Stefano Fumo, D. Paterna, M. Serpico, "Aerothermodynamic study of UHTC-based thermal protection systems", Aerospace Sci. Technol., vol. 9,no. 2, pp. 151-160, 2005.

[26] L. Scatteia, D. Alfano, S. Cantoni, F. Monteverde, M. De Stefano, A. Di Maso, R. Savino, "High Temperature, Long Duration Plasma Torch Test of a UHTC Nose Cone Demonstrator", $59^{\text {th }}$ International Astronautical Congress, 29 September - 3 October 2001, Glasgow, IAC-08- C2.4.2.

[27] Andrew J. Lofthouse, "Nonequilibrium Hypersonic Aerothermodynamics Using the Direct Simulation Montecarlo and Navier Stockes Models", A dissertation submitted in partial fulfillment of the requirements for the degree of Doctor of Philosophy (Aerospace Engineering) in The University of Michigan 2008.

(c) Savino et al.; Licensee Bentham Open.

This is an open access article licensed under the terms of the Creative Commons Attribution Non-Commercial License (http: //creativecommons.org/licenses/bync/3.0/) which permits unrestricted, non-commercial use, distribution and reproduction in any medium, provided the work is properly cited. 